\title{
Contemporary surgical management of inflammatory breast cancer: a narrative review
}

\author{
Taiwo Adesoye ${ }^{1}$, Shelby Irwin ${ }^{1}$, Susie X. Sun ${ }^{1,2}$, Anthony Lucci $^{1,2}$, Mediget Teshome $^{1,2}$ \\ ${ }^{1}$ Department of Breast Surgical Oncology, The University of Texas MD Anderson Cancer Center, Houston, TX, USA; ${ }^{2}$ Morgan Welch Inflammatory \\ Breast Cancer Research Program and Clinic, The University of Texas MD Anderson Cancer Center, Houston, TX, USA \\ Contributions: (I) Conception and design: All authors; (II) Administrative support: T Adesoye, M Teshome; (III) Provision of study materials or \\ patients: T Adesoye, M Teshome; (IV) Collection and assembly of data: T Adesoye, M Teshome; (V) Data analysis and interpretation: T Adesoye, SX \\ Sun, A Lucci, M Teshome; (VI) Manuscript writing: All authors; (VII) Final approval of manuscript: All authors. \\ Correspondence to: Mediget Teshome, MD, MPH, FACS. Department of Breast Surgical Oncology, The University of Texas MD Anderson Cancer \\ Center, 1400 Pressler Street, Unit 1434, Houston, TX 77030, USA. Email: MTeshome@mdanderson.org.
}

Objective: The purpose of this review is to outline the surgical management of inflammatory breast cancer (IBC) including the clinical decision making, operative approach and current controversies.

Background: IBC is a rare and aggressive form of breast cancer. Trimodality therapy consisting of neoadjuvant therapy, modified radical mastectomy (MRM) and radiation therapy improves survival and is the recommended course of treatment. Advancements in systemic therapy and de-escalation strategies in non-IBC have accelerated discussions regarding several aspects of care in IBC including feasibility of deescalation of surgical care, timing of reconstruction and the role of surgery in de novo stage IV disease. We discuss the evidence to support the surgical approach and decision-making in this rare disease.

Methods: We reviewed existing literature using multiple electronic databases and clinical consensus guidelines to identify historical and current publications addressing current management recommendations and clinical controversies in IBC.

Conclusions: Breast conserving surgery (BCS), skin- or nipple-sparing mastectomy should not be performed in IBC as surgical resection to negative margins results in improved locoregional recurrence rates. Level I and II axillary lymph node dissection should be performed regardless of response to therapy and initial nodal status. Reconstruction should be delayed and contralateral prophylactic mastectomy (CPM) is discouraged in IBC. Surgery may be considered for de novo stage IV IBC patients who demonstrate durable response to neoadjuvant therapy to improve local-regional control.

Keywords: Inflammatory breast cancer (IBC); trimodality therapy; surgery; post mastectomy radiation therapy; lymphedema

Submitted Aug 13, 2021. Accepted for publication Dec 15, 2021.

doi: $10.21037 /$ cco-21-113

View this article at: https://dx.doi.org/10.21037/cco-21-113

\section{Introduction}

The management of breast cancer has dramatically changed over the past 6 decades from primarily a surgical disease to leveraging a multidisciplinary approach with recognition of breast cancer as a systemic disease. Improved survival outcomes have been largely driven by sophisticated understanding of breast cancer subtypes and improved systemic therapies including targeted therapy. This has allowed for the refinement of surgical approaches including de-escalation in select patient populations. Despite this, surgery remains critically important within the multidisciplinary treatment paradigm. Specifically, surgical management not only results in excision of the malignancy but also clarifies the pathologic stage or response to treatment, provides local-regional control and remains essential for curative intent therapy. 

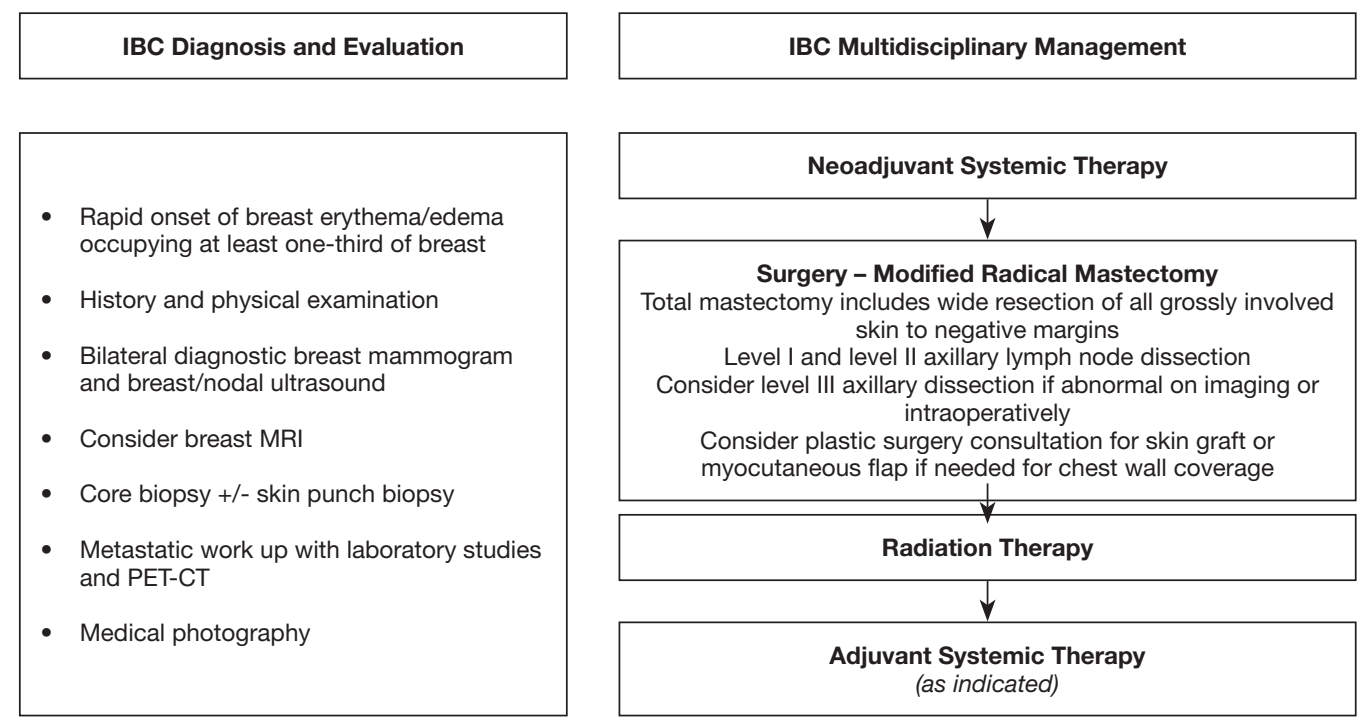

Figure 1 Diagnosis, evaluation and treatment algorithm for non-metastatic inflammatory breast cancer (IBC).

Inflammatory breast cancer (IBC) is a rare and aggressive breast malignancy accounting for approximately $2-5 \%$ of breast cancer cases (1). IBC is characterized by rapid onset of distinctive findings including erythema, peau d'orange, skin thickening and edema involving at least one-third of the breast (Figure 1) $(2,3)$. These classic findings are secondary to dermal lymphatic involvement with the pathognomonic histopathologic finding of tumor emboli in the dermal lymphatics present in up to $75 \%$ of IBC cases though a positive skin biopsy is not required for diagnosis (4). IBC is a clinical diagnosis with patients classified as stage III or IV and patients often present with extensive involvement of the breast skin, breast and axillary nodes.

To better understand biological differences between IBC and non-IBC, genomic sequencing has been applied to identify unique gene expression profiles in IBC for potential targeted strategies (5-8). Despite these efforts, distinct genomic differences between IBC and non-IBC are yet to be clearly defined. However, the importance of cells in the tumor microenvironment such as macrophages, dendritic cells and endothelial cells (9-11), have emerged as potential pathways contributing to the aggressive nature of IBC and is under further investigation in collaborative efforts across institutions (5). Challenges include the rarity of IBC, the diverse molecular subtypes, and difficulty with obtaining tissue specimen pre-, during and post-treatment.

Though it represents a small proportion of total breast cancer cases, IBC is disproportionately responsible for approximately $10 \%$ of breast cancer deaths. Historical studies showed extremely poor prognosis with surgery alone (12). It is now well established that trimodality therapy with neoadjuvant systemic therapy followed by surgery and radiation is associated with improved survival outcomes (13-15). Additional adjuvant therapy is also often indicated in current practice depending on treatment response and approximated tumor subtype. Contemporary survival outcomes have greatly improved reaching $69 \%$ at 5 years although still are not equivalent to non-IBC (16).

The proportion of molecular subtypes in IBC differ when compared to non-IBC with IBC demonstrating a higher proportion of triple negative breast cancer (TNBC) and HER2-positive subtypes representing 30\% and $40 \%$ of cases respectively, while hormone receptor (HR)-positive subtype is the predominant subtype in non-IBC. Similar to non-IBC, higher pathologic complete response (pCR) rates are observed for TNBC and HER2 positive and pCR is highly prognostic in all subtypes $(5,17,18)$. When evaluating IBC outcomes by subtype, TNBC subtype is shown to have worse outcomes compared to other molecular subtypes. Unlike in non-IBC, HR-positive status does not confer favorable prognosis and same stage disease has significantly worse prognosis in IBC compared to non$\operatorname{IBC}(17,19)$.

This article focuses on the rationale and principles guiding surgical therapy for IBC and the optimal operative approach for treating the breast primary and axillary nodes, with discussion of long-term sequalae and current controversies. 


\begin{tabular}{|c|c|c|}
\hline Preoperative & Intraoperative & Postoperative \\
\hline $\begin{array}{l}\text { - Thorough evaluation at } \\
\text { presentation to determine extent } \\
\text { of tumor involvement in the skin, } \\
\text { breast tissue and nodal basins } \\
\text { - Serial medical photography and } \\
\text { breast imaging at presentation } \\
\text { and during therapy to monitor } \\
\text { response } \\
\text { - Referral to plastic surgery if } \\
\text { chest wall coverage with skin } \\
\text { graft or myocutaneous flap is } \\
\text { anticipated } \\
\text { - Preoperative lymphedema arm } \\
\text { measurements and counseling } \\
\text { Optimization of co-morbidities }\end{array}$ & $\begin{array}{l}\text { - Total mastectomy to include wide } \\
\text { resection of all grossly involved skin with } \\
\text { goal of negative margins } \\
\text { - Level I and II axillary lymph node } \\
\text { dissection, consider level III lymph } \\
\text { node dissection if abnormal nodes are } \\
\text { identified pre- or intraoperatively } \\
\text { Collaboration with plastic surgery as } \\
\text { indicated for chest wall coverage } \\
\text { Contraindicated } \\
\text { Breast conserving surgery } \\
\text { Sentinel node dissection } \\
\text { Targeted axillary dissection } \\
\text { Contralateral prophylactic mastectomy } \\
\text { Immediate breast reconstruction }\end{array}$ & $\begin{array}{l}\text { - } \begin{array}{l}\text { Comprehensive review } \\
\text { of surgical pathology } \\
\text { with multidisciplinary } \\
\text { discussion }\end{array} \\
\text { - } \text { Re-excision to negative } \\
\text { margins if indicated } \\
\text { - Lymphedema arm } \\
\text { measurements for } \\
\text { surveillance } \\
\text { Provide post- } \\
\text { mastectomy bra and } \\
\text { prosthesis } \\
\text { Delayed breast } \\
\text { reconstruction if desired } \\
\text { by the patient }\end{array}$ \\
\hline
\end{tabular}

Figure 2 Surgical principles and decision-making in inflammatory breast cancer (IBC).

We present the following article in accordance with the Narrative Review reporting checklist (available at https:// dx.doi.org/10.21037/cco-21-113).

\section{Surgical management of IBC}

Modified radical mastectomy (MRM) after neoadjuvant systemic therapy remains the standard of care in the surgical management of non-metastatic IBC (20). Trimodality therapy including MRM is an independent predictor of longterm survival $(15,21)$. MRM consists of a total mastectomy, in which the nipple, areola and central breast skin is excised with the underlying breast tissue, as well as an axillary lymph node dissection, excising the ipsilateral level I and II axillary nodes. The goal of surgery is to achieve pathologically negative margins and in IBC, it is important to excise all grossly involved skin and often results in a more extensive skin excision than non-IBC. Consultation with a plastic surgeon may be needed for skin graft or flap closure for chest wall coverage in the setting of extensive skin resection. Furthermore, if the underlying pectoralis muscle is involved this should be excised en bloc (partial or full resection). Additionally, axillary dissection is recommended regardless of response to therapy and initial nodal status. In patients with abnormal level III lymph nodes identified preoperatively or during surgery, a level III dissection may be performed. The efficacy of skin or nipple sparing mastectomy has not been demonstrated in IBC and is contraindicated given the extensive skin involvement. (Figure 2).

In a study of 114 patients with non-metastatic IBC,
Rosso et al. demonstrated the importance of aggressive surgical resection to negative margins in improving LRR rates. In this cohort, approximately $40 \%$ had N2/N3 disease and all patients received trimodality therapy with curative intent. Surgical margins were negative in $99 \%$ of patients ( $\mathrm{n}=113)$, and positive in one patient. Only 4 patients developed locoregional recurrence and 4-year probability of locoregional recurrence was 5.6\% (95\% CI: 2.76-14.7\%) (16). In this study, 2 patients developed complications; mild incisional necrosis managed non-operatively in 1 patient, and partial incision breakdown managed with surgical debridement in another. Locoregional recurrence in IBC carries a poor prognosis and can be resistant to local and systemic therapy. As such, consensus guidelines support aggressive locoregional control with MRM, followed by post-mastectomy radiation therapy (PMRT) as essential for optimal outcomes in IBC (22).

\section{Breast conserving surgery (BCS)}

It is well established that neoadjuvant systemic therapy may be utilized to facilitate breast conservation in locally advanced non-IBC patients with exceptional response to therapy $(23,24)$, however, there is limited data to suggest benefit in IBC. A SEER study evaluating the impact of locoregional therapy on survival in IBC demonstrated that total mastectomy was associated with improved survival (HR 0.75, 95\% CI: 0.65-0.85) compared to partial mastectomy, and radiation therapy also improved survival (HR 0.64, 95\% CI: 0.61-0.69) (25). A retrospective analysis investigating 
the feasibility of de-escalating breast surgery in IBC evaluated 35 patients diagnosed from 1999 to 2013 (26). Neoadjuvant chemotherapy was administered to 20 patients and 14 received neoadjuvant endocrine therapy (NET). The decision for BCS was made by the treating physician based on response to therapy. After 80 months of follow up, 5-year local-regional recurrence (LRR) free survival was $87.5 \%$ (95\% CI: $76.0-99.0 \%$ ) and overall survival was $70.3 \%$ (95\% CI: 54.8-85.8\%) (26). These favorable results should be reviewed with caution as the cohort did not reflect the typical IBC patient. Most patients presented with a unifocal mass but an underlying mass is only present in about $50 \%$ of IBC cases (27). In addition, nodal burden was minimal in this cohort which is unusual for IBC (28).

\section{Sentinel lymph node dissection (SLND)}

SLND is the standard of care for axillary staging in clinically node negative breast cancer and increasingly employed in node positive patients after neoadjuvant chemotherapy. Successful SLND requires the ability to identify the SLNs with high reliability and accuracy.

The majority of IBC patients have nodal metastasis at presentation. In an analysis of a prospective institutional database, $90 \%$ of IBC patients had at least N1 disease identified on axillary ultrasound and fine needle aspiration (FNA) (28). For this reason, ALND is the recommended treatment for the axilla and de-escalation of axillary surgery is discouraged. Several trials investigating the feasibility of sentinel lymph node biopsy after NACT in IBC demonstrated a high false negative rate (FNR) ranging from 18.2 to $25 \%$ and identification rate ranging from $25-80 \%$ (29-31). Using dual-tracer technique in a prospective trial of 16 patients, DeSnyder et al. showed an identification rate of only $25 \%$ with three quarters of the patients with identifiable sentinel nodes having an axillary nodal PCR (30). This is in stark contrast to non-IBC where sentinel node identification rates are consistently $>90 \%$. The lack of accuracy and reliability of identification of sentinel nodes precludes this approach in IBC.

Furthermore, SLND in women with clinically nodepositive breast cancer treated with neoadjuvant chemotherapy has been studied in several large prospective clinical trials with refined technique of targeted axillary dissection (TAD) increasingly employed. TAD involves removal of the sentinel lymph node(s) using dual tracer technique and selective excision of the clipped node biopsy proven axillary node has shown FNR of $2.0 \%(32,33)$. Additionally, TAD is most effective in patients with limited nodal disease. Up to a third of IBC patients have pathologically negative lymph node status (ypN0) after NACT (28). As with non-IBC, IBC patients with HER2+ disease have a high likelihood of achieving pCR after NACT approximating $64 \%$ in a single institution review (34-36). While it is tempting to extrapolate de-escalation strategies for node-positive breast cancer patients treated with neoadjuvant chemotherapy, it should be noted that the foundational studies did not include patients with IBC. These findings may inform the selection of IBC patients for de-escalation of axillary surgery however future studies are needed before adopting this approach.

\section{Immediate post-mastectomy reconstruction}

Immediate post-mastectomy reconstruction has been associated with several advantages including improved patient satisfaction and body image. To facilitate immediate reconstruction, skin or nipple sparing mastectomy is typically performed to preserve the skin envelope for placement of a tissue expander/implant or autologous flap. In IBC given the extensive skin involvement, skin sparing and nipple sparing approaches are contraindicated. Immediate breast reconstruction is not recommended in IBC due to the high risk of recurrence, potential to delay receipt of PMRT and the complexity of the reconstruction needed secondary to extensive resection (37). PMRT is essential for optimal oncologic outcomes in the management of IBC however, it may result in complications during reconstruction and worse cosmetic outcomes as well as suboptimal patient satisfaction $(38,39)$. As such, delayed reconstruction with autologous flap approach is recommended in IBC patients who desire post-mastectomy reconstruction. The optimal timing of reconstruction after PMRT is uncertain although one study showed fewer complications with a 12-month delay (40).

\section{Contralateral prophylactic mastectomy (CPM)}

In the United States, national trends indicate increased utilization of CPM despite advances in adjuvant therapy (41-44). While effective as a strategy for risk reduction of breast cancer in women with high-risk for breast cancer, this approach has shown no survival advantage in averagerisk women with unilateral breast cancer (45-46). The competing risk of mortality from the index malignancy is an important decision-making factor when considering CPM. In 2016, the American Society of Breast Surgeons (ASBrS) 
Table 1 Retrospective studies evaluating primary tumor surgery in de novo stage IV Inflammatory breast cancer

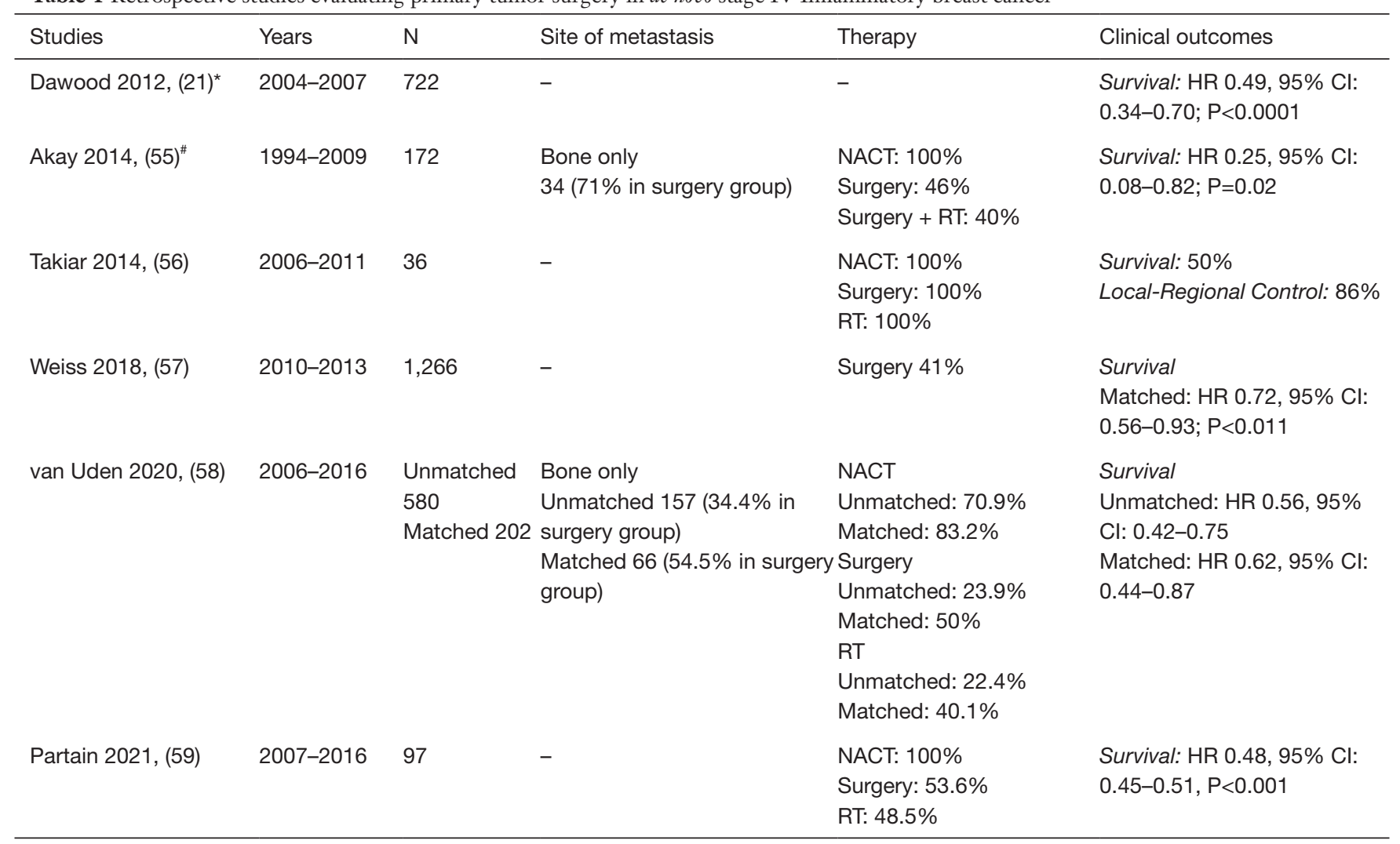

*, therapy and site of metastasis data provided included stage III patients. No data on HER2 status or trastuzumab therapy; ", trastuzumab after 2001. NACT, neoadjuvant chemotherapy; RT, radiation therapy.

published a consensus statement on CPM and determined that for patients with IBC, given the aggressive primary malignancy, routine CPM is discouraged (47). Furthermore, several studies have shown increased risk of complications following bilateral mastectomy as compared to unilateral mastectomy in addition to higher costs (48-51). In IBC this is highly clinically relevant as surgical complications can delay essential adjuvant therapies such as post-mastectomy radiation and delay in treatment may result in suboptimal oncologic outcomes. Furthermore, CPM can be deferred to the time of definitive breast reconstruction if strongly desired by the patient and there is no evidence of disease (NED).

\section{Rationale for surgery in de novo stage IV IBC}

Surgery in stage IV breast cancer remains controversial with NCCN guidelines indicating the decision should be made in a multidisciplinary setting on a case by case basis (3). Traditionally, this was reserved for palliation of symptoms given no known survival benefit. However, this a heterogenous patient population with improving outcomes particularly those who achieve NED status. While several retrospective studies have shown a survival benefit for surgery in de novo stage IV breast cancer, prospective studies have shown conflicting results.

Approximately $30 \%$ of IBC patients present with de novo stage IV disease compared to $6-10 \%$ in non-IBC disease (52-54). While current recommendations support surgical therapy in stage III disease where the treatment approach is for curative intent, there is less consensus on the role of surgery in stage IV disease particularly given prospective studies have not shown a survival benefit. Current practice remains to prioritize systemic therapy as the primary treatment modality and consider local regional therapy in patients with a significant and/or durable treatment response.

Neoadjuvant systemic therapy with anthracycline-based chemotherapy and dual anti-HER2 targeted therapy in HER2+ disease remains first line treatment in stage IV IBC despite the results of several retrospective studies $(20,21,55-59)$ (Table 1). In IBC where there are extensive skin and chest 
wall findings, surgery in combination with radiation may be considered for local control due to significant morbidity associated with uncontrolled chest wall disease. In a retrospective analysis, Partain et al. evaluated the role of MRM in a contemporary cohort of de novo stage IV IBC treated with systemic and targeted therapy (59). After a median follow up of 70 months, LRR occurred in 6 of 47 patients who received trimodality therapy. Five patients had clinical partial response, and one had clinical complete response and also had pCR (59). In an inverse probability weighted analysis, favorable response to NAST with partial or complete response compared to stable or progressive disease (HR 0.49, 95\% CI: 0.46-0.52, $\mathrm{P}<0.001$ ) and surgical intervention with MRM (HR 0.48, 95\% CI: 0.45-0.51, $\mathrm{P}<0.001)$ were independently associated with decreased risk of death. In a nationwide population-based cancer registry in the Netherlands using propensity score matching, surgery was also independently associated with improved survival (HR 0.62, 95\% CI: 0.44-0.87) (58).

Several randomized controlled trials in non-IBC assessing impact of surgical therapy in stage IV disease report conflicting findings (60-62). Soran et al. demonstrated improved survival with locoregional therapy after 5 years in patients with no prior systemic therapy. Patients who underwent surgery did have higher rates of ER+ tumors and single bone metastasis compared to patients in the systemic chemotherapy arm. Furthermore, the sequence of surgery prior to systemic therapy in stage IV disease is unlikely in this era (61). This contrasts with the recent ECOG-ACRIN 2108 trial demonstrating no difference in 3 -year OS for surgery $v s$. no surgery in de novo metastatic breast cancer patients without progression after NAST (68.4\% vs. 67.9\%; HR 1.09; 95\% CI: 0.80-1.49; $\mathrm{P}=0.63)$ (62). There was also no significant difference in quality of life at 30 months after randomization. One critique of the study is the advanced disease stage in the patient population and the $20 \%$ margin positivity rate in patients who underwent surgery (62).

De novo Stage IV disease with isolated contralateral axilla metastasis (CAM) occurs in $8.3 \%$ of IBC patients (63). In this scenario, comprehensive local regional treatment with axillary dissection and radiation can achieve NED status.

In the absence of clinical trials to inform practice in IBC patients, we recommend local-regional therapy with surgery and radiation should be considered in patients who demonstrate durable response to NAST and remain an option for patients with rapidly progressing or symptomatic disease. It is important that this decision is made in the context of a multidisciplinary team as well as disclosure to the patient regarding the benefit for local-regional control with unclear impact on survival, operative risks and longterm side effects including lymphedema and body image concerns.

\section{Long-term sequalae of surgery: lymphedema}

With improving survival outcomes, long term sequelae from surgical therapies are becoming increasingly important and significant for breast cancer survivors. Breast-associated lymphedema is characterized by progressive swelling of the chest/upper extremity following breast cancer therapy due to impairment of lymph drainage via lymphatic channels. This may develop immediately after therapy or decades after treatment. Locoregional treatment with ALND (64-66) and regional nodal irradiation $(67,68)$ are independent risk factors for the development of lymphedema and reported to be as high as $60 \%$ when both therapies are combined $(69,70)$. While there is paucity of data regarding incidence of lymphedema in IBC, patients with IBC are considered especially high risk given locoregional therapy with surgery and PMRT is standard of care. In patients who have developed lymphedema, management includes compression therapy and therapeutic exercises with trained lymphedema therapists (71). Microsurgical techniques such as lymphovenous bypass and vascularized lymph node transfers have been investigated as therapeutic and prophylactic interventions in high-risk patients with favorable outcomes (72). Another technique known as reverse axillary mapping involves injection of blue dye into the subcutaneous upper extremity and to identify the blue arm lymphatics in the axilla and anastomosing the arm lymphatics with adjacent veins at the time of surgery. An $80 \%$ decrease rate has been reported when axillary reverse mapping and lymphovenous bypass are performed (73-75). We recommended patient education, early screening and consideration of preventive methods with expertise in microsurgery in IBC patients.

\section{Conclusions}

Surgery remains a critical element in the multidisciplinary management of IBC. Standard of care remains trimodal therapy, including neoadjuvant systemic therapy followed by MRM and post-mastectomy radiation therapy as supported by international consensus guidelines (22). BCS, SLND, skin and nipple sparing mastectomy, immediate 
breast reconstruction and CPM are not recommended treatment strategies. Local-regional therapy with surgery and radiation improves local-regional outcomes in patients with de novo stage IV disease. Future studies are needed prior to adopting de-escalation strategies in this patient population with aggressive high-risk disease biology and where continued strides in survival outcomes are needed.

\section{Acknowledgments}

Funding: Institutional database supported by Morgan Welch Inflammatory Breast Cancer Research Program, and State of Texas Rare and Aggressive Breast Cancer Research Program Grant.

\section{Footnotes}

Provenance and Peer Review: This article was commissioned by the Guest Editors (Naoto Ueno and Angela Alexander) for the series "Inflammatory Breast Cancer" published in Chinese Clinical Oncology. The article has undergone external peer review.

Reporting Checklist: The authors have completed the Narrative Review reporting checklist. Available at https:// dx.doi.org/10.21037/cco-21-113

Conflicts of Interest: All authors have completed the ICMJE uniform disclosure form (available at https://dx.doi. org/10.21037/cco-21-113). The series "Inflammatory Breast Cancer" was commissioned by the editorial office without any funding or sponsorship. The authors have no other conflicts of interest to declare.

Ethical Statement: The authors are accountable for all aspects of the work in ensuring that questions related to the accuracy or integrity of any part of the work are appropriately investigated and resolved.

Open Access Statement: This is an Open Access article distributed in accordance with the Creative Commons Attribution-NonCommercial-NoDerivs 4.0 International License (CC BY-NC-ND 4.0), which permits the noncommercial replication and distribution of the article with the strict proviso that no changes or edits are made and the original work is properly cited (including links to both the formal publication through the relevant DOI and the license). See: https://creativecommons.org/licenses/by-nc-nd/4.0/.

\section{References}

1. Dawood S. Biology and management of inflammatory breast cancer. Expert Rev Anticancer Ther 2010;10:209-20.

2. Dawood S, Merajver SD, Viens P, et al. International expert panel on inflammatory breast cancer: consensus statement for standardized diagnosis and treatment. Ann Oncol 2011;22:515-23.

3. National Comprehensive Cancer Network. Clinical Practice Guidelines in Oncology (version 5.2021). Accessed 7 Jul 2021. Available online: https://www.nccn.org/

4. Vermeulen PB, van Golen KL, Dirix LY. Angiogenesis, lymphangiogenesis, growth pattern, and tumor emboli in inflammatory breast cancer: a review of the current knowledge. Cancer 2010;116:2748-54.

5. Lim B, Woodward WA, Wang X, et al. Inflammatory breast cancer biology: the tumour microenvironment is key. Nat Rev Cancer 2018;18:485-99.

6. Iwamoto T, Bianchini G, Qi Y, et al. Different gene expressions are associated with the different molecular subtypes of inflammatory breast cancer. Breast Cancer Res Treat 2011;125:785-95.

7. Van der Auwera I, Limame R, van Dam P, et al. Integrated miRNA and mRNA expression profiling of the inflammatory breast cancer subtype. Br J Cancer 2010;103:532-41.

8. Van Laere SJ, Ueno NT, Finetti P, et al. Uncovering the molecular secrets of inflammatory breast cancer biology: an integrated analysis of three distinct affymetrix gene expression datasets. Clin Cancer Res 2013;19:4685-96.

9. Wolfe AR, Trenton NJ, Debeb BG, et al. Mesenchymal stem cells and macrophages interact through IL-6 to promote inflammatory breast cancer in pre-clinical models. Oncotarget 2016;7:82482-92.

10. Mego M, Gao H, Cohen EN, et al. Circulating tumor cells (CTCs) are associated with abnormalities in peripheral blood dendritic cells in patients with inflammatory breast cancer. Oncotarget 2017;8:35656-68.

11. Colpaert CG, Vermeulen PB, Benoy I, et al. Inflammatory breast cancer shows angiogenesis with high endothelial proliferation rate and strong E-cadherin expression. $\mathrm{Br} \mathrm{J}$ Cancer 2003;88:718-25.

12. Droulias CA, Sewell CW, Mcsweeney MB, et al. Inflammatory carcinoma of the breast: A correlation of clinical, radiologic and pathogic findings. Ann Surg 1976;184:217-22.

13. Vergés R, Felip E, Alastuey I, et al. Combined chemotherapy, radiotherapy and surgery in inflammatory 
breast carcinoma. Acta Oncol 1995;34:123-4.

14. Low JA, Berman AW, Steinberg SM, et al. Long-term follow-up for locally advanced and inflammatory breast cancer patients treated with multimodality therapy. J Clin Oncol 2004;22:4067-74.

15. Rueth NM, Lin HY, Bedrosian I, et al. Underuse of trimodality treatment affects survival for patients with inflammatory breast cancer: an analysis of treatment and survival trends from the National Cancer Database. J Clin Oncol 2014;32:2018-24.

16. Rosso KJ, Tadros AB, Weiss A, et al. Improved Locoregional Control in a Contemporary Cohort of Nonmetastatic Inflammatory Breast Cancer Patients Undergoing Surgery. Ann Surg Oncol 2017;24:2981-8.

17. Li J, Gonzalez-Angulo AM, Allen PK, et al. Triplenegative subtype predicts poor overall survival and high locoregional relapse in inflammatory breast cancer. Oncologist 2011;16:1675-83.

18. Menta A, Fouad TM, Lucci A, et al. Inflammatory Breast Cancer: What to Know About This Unique, Aggressive Breast Cancer. Surg Clin North Am 2018;98:787-800.

19. Masuda H, Brewer TM, Liu DD, et al. Long-term treatment efficacy in primary inflammatory breast cancer by hormonal receptor- and HER2-defined subtypes. Ann Oncol 2014;25:384-91.

20. National Comprehensive Cancer Network. NCCN Clinical Practice Guidelines in Oncology (NCCN Guidelines). Breast Cancer. Version 5.2021 - June 28.

21. Dawood S, Ueno NT, Valero V, et al. Identifying factors that impact survival among women with inflammatory breast cancer. Ann Oncol 2012;23:870-5.

22. Ueno NT, Espinosa Fernandez JR, Cristofanilli M, et al. International Consensus on the Clinical Management of Inflammatory Breast Cancer from the Morgan Welch Inflammatory Breast Cancer Research Program 10th Anniversary Conference. J Cancer 2018;9:1437-47.

23. Fisher B, Brown A, Mamounas E, et al. Effect of preoperative chemotherapy on local-regional disease in women with operable breast cancer: findings from National Surgical Adjuvant Breast and Bowel Project B-18. J Clin Oncol 1997;15:2483-93.

24. Shen J, Valero V, Buchholz TA, et al. Effective local control and long-term survival in patients with T4 locally advanced breast cancer treated with breast conservation therapy. Ann Surg Oncol 2004;11:854-60.

25. Muzaffar M, Johnson HM, Vohra NA, et al. The Impact of Locoregional Therapy in Nonmetastatic Inflammatory Breast Cancer: A Population-Based Study. Int J Breast
Cancer 2018;2018:6438635.

26. Brzezinska M, Williams LJ, Thomas J, et al. Outcomes of patients with inflammatory breast cancer treated by breast-conserving surgery. Breast Cancer Res Treat 2016;160:387-91.

27. Fouad TM, Barrera AMG, Reuben JM, et al. Inflammatory breast cancer: a proposed conceptual shift in the UICC-AJCC TNM staging system. Lancet Oncol 2017;18:e228-32.

28. Postlewait LM, Teshome M, DeSnyder SM, et al. Factors Associated with Pathological Node Negativity in Inflammatory Breast Cancer: Are There Patients Who May be Candidates for a De-Escalation of Axillary Surgery? Ann Surg Oncol 2020;27:4603-12.

29. Stearns V, Ewing CA, Slack R, et al. Sentinel lymphadenectomy after neoadjuvant chemotherapy for breast cancer may reliably represent the axilla except for inflammatory breast cancer. Ann Surg Oncol 2002;9:235-42

30. DeSnyder SM, Mittendorf EA, Le-Petross C, et al. Prospective Feasibility Trial of Sentinel Lymph Node Biopsy in the Setting of Inflammatory Breast Cancer. Clin Breast Cancer 2018;18:e73-7.

31. Hidar S, Bibi M, Gharbi O, et al. Sentinel lymph node biopsy after neoadjuvant chemotherapy in inflammatory breast cancer. Int J Surg 2009;7:272-5.

32. Boughey JC, Ballman KV, Le-Petross HT, et al. Identification and Resection of Clipped Node Decreases the False-negative Rate of Sentinel Lymph Node Surgery in Patients Presenting With Node-positive Breast Cancer (T0-T4, N1-N2) Who Receive Neoadjuvant Chemotherapy: Results From ACOSOG Z1071 (Alliance). Ann Surg 2016;263:802-7.

33. Caudle AS, Yang WT, Krishnamurthy S, et al. Improved Axillary Evaluation Following Neoadjuvant Therapy for Patients With Node-Positive Breast Cancer Using Selective Evaluation of Clipped Nodes: Implementation of Targeted Axillary Dissection. J Clin Oncol 2016;34:1072-8.

34. Grova MM, Strassle PD, Navajas EE, et al. The Prognostic Value of Axillary Staging Following Neoadjuvant Chemotherapy in Inflammatory Breast Cancer. Ann Surg Oncol 2021;28:2182-90.

35. Nakhlis F, Regan MM, Warren LE, et al. The Impact of Residual Disease After Preoperative Systemic Therapy on Clinical Outcomes in Patients with Inflammatory Breast Cancer. Ann Surg Oncol 2017;24:2563-9.

36. Imeokparia FO, Hughes TM, Dossett LA, et al. Axillary Pathologic Complete Response in Inflammatory Breast 
Cancer Patients: Implications for SLNB? Ann Surg Oncol 2019;26:3374-9.

37. National Comprehensive Cancer Network. NCCNBCV. (March 16, 2021). Accessed 7 Jul 2021. Available online: https://www.nccn.org/

38. Kelley BP, Ahmed R, Kidwell KM, et al. A systematic review of morbidity associated with autologous breast reconstruction before and after exposure to radiotherapy: are current practices ideal? Ann Surg Oncol 2014;21:1732-8.

39. Schaverien MV, Macmillan RD, McCulley SJ. Is immediate autologous breast reconstruction with postoperative radiotherapy good practice?: a systematic review of the literature. J Plast Reconstr Aesthet Surg 2013;66:1637-51.

40. Baumann DP, Crosby MA, Selber JC, et al. Optimal timing of delayed free lower abdominal flap breast reconstruction after postmastectomy radiation therapy. Plast Reconstr Surg 2011;127:1100-6.

41. Borzekowski DL, Guan Y, Smith KC, et al. The Angelina effect: immediate reach, grasp, and impact of going public. Genet Med 2014;16:516-21.

42. Panchal H, Pilewskie ML, Sheckter CC, et al. National trends in contralateral prophylactic mastectomy in women with locally advanced breast cancer. J Surg Oncol 2019;119:79-87.

43. King TA, Sakr R, Patil S, et al. Clinical management factors contribute to the decision for contralateral prophylactic mastectomy. J Clin Oncol 2011;29:2158-64.

44. Tuttle TM, Habermann EB, Grund EH, et al. Increasing use of contralateral prophylactic mastectomy for breast cancer patients: a trend toward more aggressive surgical treatment. J Clin Oncol 2007;25:5203-9.

45. Portschy PR, Kuntz KM, Tuttle TM. Survival outcomes after contralateral prophylactic mastectomy: a decision analysis. J Natl Cancer Inst 2014;106:dju160.

46. Lostumbo L, Carbine NE, Wallace J. Prophylactic mastectomy for the prevention of breast cancer. Cochrane Database Syst Rev 2010;(11):CD002748.

47. Boughey JC, Attai DJ, Chen SL, et al. Contralateral Prophylactic Mastectomy (CPM) Consensus Statement from the American Society of Breast Surgeons: Data on CPM Outcomes and Risks. Ann Surg Oncol 2016;23:3100-5.

48. Boughey JC, Attai DJ, Chen SL, et al. Contralateral Prophylactic Mastectomy Consensus Statement from the American Society of Breast Surgeons: Additional Considerations and a Framework for Shared Decision Making. Ann Surg Oncol 2016;23:3106-11.
49. Roberts A, Habibi M, Frick KD. Cost-effectiveness of contralateral prophylactic mastectomy for prevention of contralateral breast cancer. Ann Surg Oncol 2014;21:2209-17.

50. Miller ME, Czechura T, Martz B, et al. Operative risks associated with contralateral prophylactic mastectomy: a single institution experience. Ann Surg Oncol 2013;20:4113-20.

51. Crosby MA, Garvey PB, Selber JC, et al. Reconstructive outcomes in patients undergoing contralateral prophylactic mastectomy. Plast Reconstr Surg 2011;128:1025-33.

52. Wingo PA, Jamison PM, Young JL, et al. Populationbased statistics for women diagnosed with inflammatory breast cancer (United States). Cancer Causes Control 2004;15:321-8.

53. Matro JM, Li T, Cristofanilli M, et al. Inflammatory breast cancer management in the national comprehensive cancer network: the disease, recurrence pattern, and outcome. Clin Breast Cancer 2015;15:1-7.

54. O'Shaughnessy J. Extending survival with chemotherapy in metastatic breast cancer. Oncologist 2005;10 Suppl 3:20-9.

55. Akay CL, Ueno NT, Chisholm GB, et al. Primary tumor resection as a component of multimodality treatment may improve local control and survival in patients with stage IV inflammatory breast cancer. Cancer 2014;120:1319-28.

56. Takiar V, Akay CL, Stauder MC, et al. Predictors of durable no evidence of disease status in de novo metastatic inflammatory breast cancer patients treated with neoadjuvant chemotherapy and post-mastectomy radiation. Springerplus 2014;3:166.

57. Weiss A, Menen RS, Lin HY, et al. Factors associated with improved outcomes for metastatic inflammatory breast cancer patients. Breast Cancer Res Treat 2018;169:615-23.

58. van Uden DJP, van Maaren MC, Strobbe LJA, et al. Better survival after surgery of the primary tumor in stage IV inflammatory breast cancer. Surg Oncol 2020;33:43-50.

59. Partain N, Postlewait LM, Teshome M, et al. The Role of Mastectomy in De novo Stage IV Inflammatory Breast Cancer. Ann Surg Oncol 2021;28:4265-74.

60. Badwe R, Hawaldar R, Nair N, et al. Locoregional treatment versus no treatment of the primary tumour in metastatic breast cancer: an open-label randomised controlled trial. Lancet Oncol 2015;16:1380-8.

61. Soran A, Ozmen V, Ozbas S, et al. Randomized Trial Comparing Resection of Primary Tumor with No Surgery in Stage IV Breast Cancer at Presentation: Protocol MF07-01. Ann Surg Oncol 2018;25:3141-9. 
62. Khan SA, Zhao F, Solin LJ, et al. A randomized phase III trial of systemic therapy plus early local therapy versus systemic therapy alone in women with de novo stage IV breast cancer: A trial of the ECOG-ACRIN Research Group (E2108). J Clin Oncol 2020;38:LBA2-LBA2.

63. Postlewait LM, Teshome M, Adesoye T, et al. Contralateral Axillary Metastasis in Patients with Inflammatory Breast Cancer. Ann Surg Oncol 2021;28:8610-21.

64. Asdourian MS, Skolny MN, Brunelle C, et al. Precautions for breast cancer-related lymphoedema: risk from air travel, ipsilateral arm blood pressure measurements, skin puncture, extreme temperatures, and cellulitis. Lancet Oncol 2016;17:e392-405.

65. Ferguson CM, Swaroop MN, Horick N, et al. Impact of Ipsilateral Blood Draws, Injections, Blood Pressure Measurements, and Air Travel on the Risk of Lymphedema for Patients Treated for Breast Cancer. J Clin Oncol 2016;34:691-8.

66. DiSipio T, Rye S, Newman B, et al. Incidence of unilateral arm lymphoedema after breast cancer: a systematic review and meta-analysis. Lancet Oncol 2013;14:500-15.

67. Shaitelman SF, Chiang YJ, Griffin KD, et al. Radiation therapy targets and the risk of breast cancer-related lymphedema: a systematic review and network metaanalysis. Breast Cancer Res Treat 2017;162:201-15.

68. Kilbreath SL, Refshauge KM, Beith JM, et al. Risk factors for lymphoedema in women with breast cancer: A large prospective cohort. Breast 2016;28:29-36.

Cite this article as: Adesoye T, Irwin S, Sun SX, Lucci A, Teshome M. Contemporary surgical management of inflammatory breast cancer: a narrative review. Chin Clin Oncol 2021;10(6):57. doi: 10.21037/cco-21-113
69. Shah C, Vicini FA. Breast cancer-related arm lymphedema: incidence rates, diagnostic techniques, optimal management and risk reduction strategies. Int J Radiat Oncol Biol Phys 2011;81:907-14.

70. Gärtner R, Jensen MB, Kronborg L, et al. Self-reported arm-lymphedema and functional impairment after breast cancer treatment--a nationwide study of prevalence and associated factors. Breast 2010;19:506-15.

71. Vignes S, Porcher R, Arrault M, et al. Long-term management of breast cancer-related lymphedema after intensive decongestive physiotherapy. Breast Cancer Res Treat 2007;101:285-90.

72. Allen RJ Jr, Cheng MH. Lymphedema surgery: Patient selection and an overview of surgical techniques. J Surg Oncol 2016;113:923-31.

73. Feldman S, Bansil H, Ascherman J, et al. Single Institution Experience with Lymphatic Microsurgical Preventive Healing Approach (LYMPHA) for the Primary Prevention of Lymphedema. Ann Surg Oncol 2015;22:3296-301.

74. Casabona F, Bogliolo S, Ferrero S, et al. Axillary reverse mapping in breast cancer: a new microsurgical lymphaticvenous procedure in the prevention of arm lymphedema. Ann Surg Oncol 2008;15:3318-9.

75. Boccardo F, Casabona F, De Cian F, et al. Lymphatic microsurgical preventing healing approach (LYMPHA) for primary surgical prevention of breast cancer-related lymphedema: over 4 years follow-up. Microsurgery 2014;34:421-4. 